\title{
Notification System to Students using an Android Application
}

\author{
May H. Riadh \\ Assistant Prof \\ Zarqa University \\ Jordan AIZarqa
}

\begin{abstract}
The goal of this paper is to design a notification system using Android application to connect it to the educational web site of the university. It achieve high and quick organize between instructor and students, save time, effort by connecting Android application to the educational database of the university using latest technologies. It provides a wide range of information about education, courses, and all about college students that help the instructor to select to whom he/she will send notifications. It also includes sending notifications, attendance, viewing academic details like exam results.
\end{abstract}

\section{Keywords}

Notification, Android application, GCM

\section{INTRODUCTION}

With the advent of mobile and pervasive computing era, smart phones became ubiquitous, and wearable devices are getting traction. A significant portion of the applications for these devices relies on remote servers on the cloud, and Google Cloud Messaging (GCM) is a popular service as a client/server communication solution for Android. [1]

Android is an open source operating system, Devices which it runs the Android application work on any mobile that support android O.S with different screen size. [2]

Android is a Linux-based, open source mobile operating system developed by Open Handset Alliance led by Google to develop apps for Android devices. To start with, must use a set of tools that are included in the Android SDK. Once downloaded and installed the SDK, anyone can access these tools right from the Eclipse IDE, through the ADT plug-in, or from the command line. Developing with Eclipse is the preferred method because it can directly invoke the tools that needed while developing applications. [3]

In this application the ADT bundle has been used that's developed by android studio. Android studio used to build a small web service that is help the mobile application to connect with My SQL database. [2]

Android is a software stack for mobile devices that includes an operating system, middleware and key applications. The Android SDK provides the tools and APIs necessary to begin developing applications on the Android platform using the Java programming language .Android based on Linux version 2.6. The system services such as security, memory management, process management are controlled by Linux $[4,6]$

\section{BASIC IDEA}

GCM is a service which allows developers to send push messages to Android devices from the server. GCM handles the queuing of the messages as well as delivering those messages to the target applications on the devices. GCM is a free service by Google, and it has no quotas. It is the default push messaging solution for the Android platform. [7]

The overall architecture of the Application is shown in Fig 2.1. Which consist of two main parts, Android application for registering and reception of notification, and a server side for the instructor to select his courses, section, student or students to send notification.

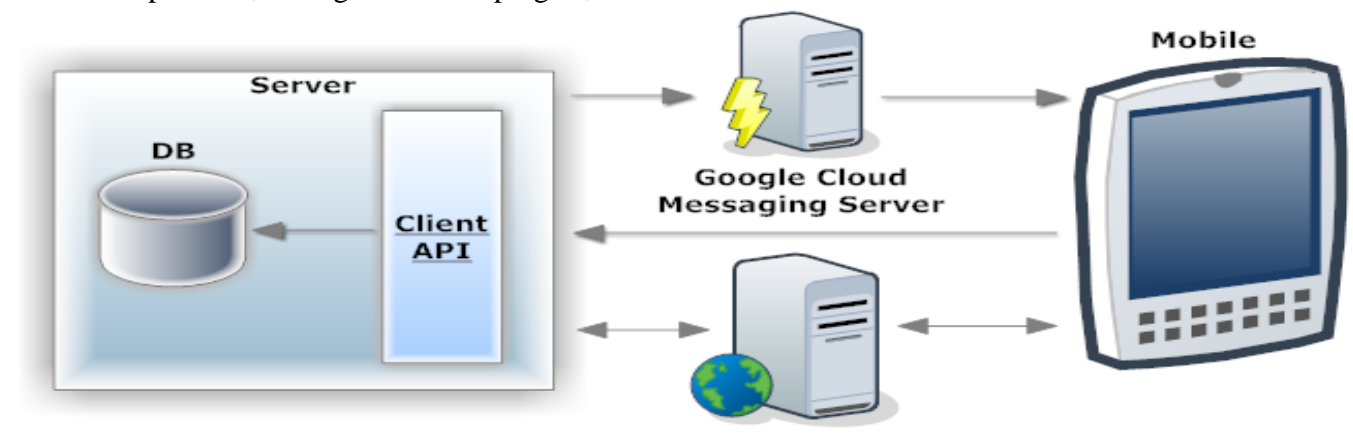

Fig 2.1 : Application Architecture

The idea based on using 'GCM' that use a web page for instructor, all information about courses and students is already exist in the e-learning application, and the client side is the android application for students.

PHP is the most commonly used as a server-side scripting language. To make PHP work as a server-side scripting language, all you need is a PHP parser, a Web server, and a
Web browser. However, the Web server has to have a connected PHP installation. [5]

The model for whole application as a single process box that represents the boundary of the application, it identifies external entities and related input and output flow as in Fig 2.2 . 
The web page gives the instructor the ability to view his courses and students in each course, select them to send a message through 'GCM' server to student's smart phone as a push notification as shown in Fig 2.3.
Students must first register through android application, which automatically finish the appropriate procedures at background as shown in Fig 2.4.

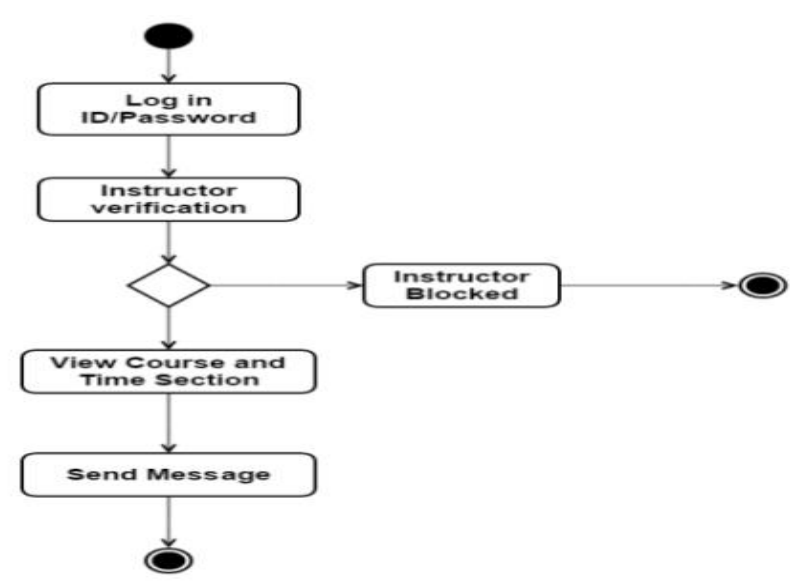

Fig 2.2 : Diagram for android student notification system

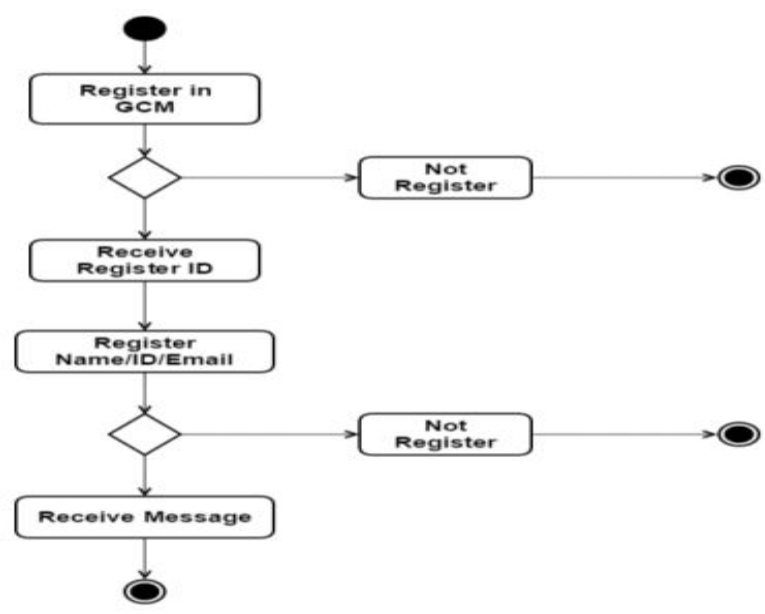

Fig 2.3 : Chart for instructor in android student notification system

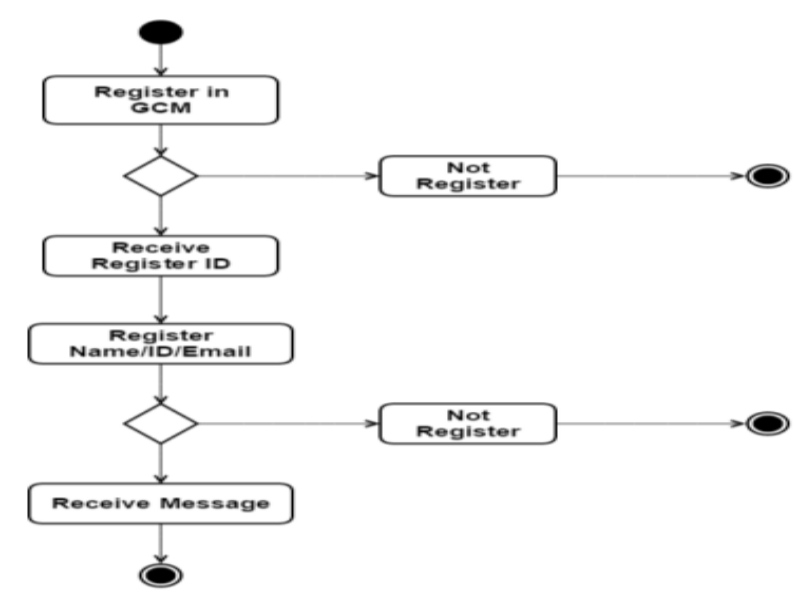

Fig 2.4 : Chart for student in android student notification system.

\section{IMPLEMENTATION}

The implementation done in two parts: the first start by loading the Android application to student mobile to establish receiving the push notification, second the web application from university side to let instructor push a notification. 


\subsection{Android Application}

The application will be loaded on Android mobile and create the icon of the application (Android student), also shows Package Google play services as shown Fig 3.1.

Run the application icon will show the register screen, registration will be done by one of the two ways:

\subsubsection{Enter info}

The student register either by enters his info as in Fig 3.2 such as (name, Gmail and University ID). The application will verify the email account by using the device Google play services and make sure that Google account is available.

\subsubsection{Scan identification card}

Second way to register is by pressing the (Scan Student ID) button as in Fig 3.2 to start download the library to read the bar code of the university identity card that is a unique number as in Fig 3.3.

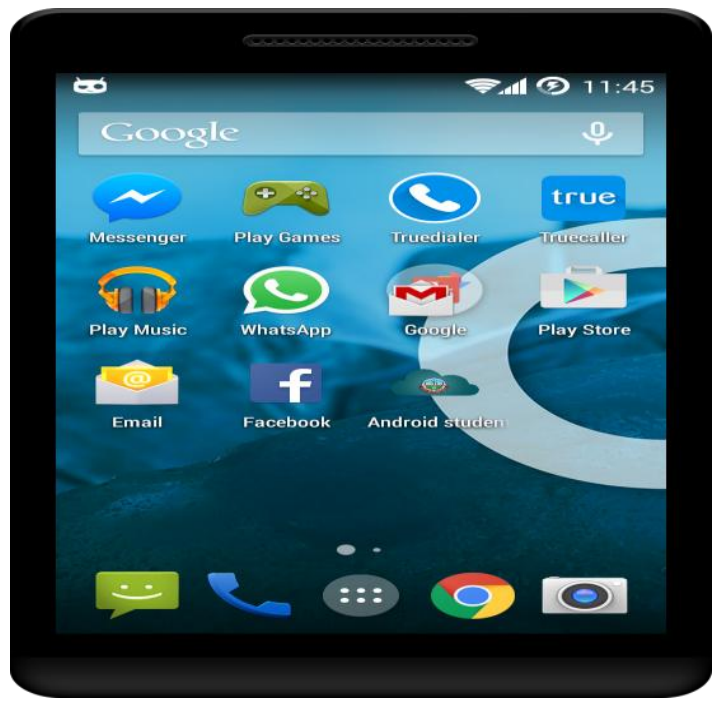

Fig 3.1 : Android Application icon

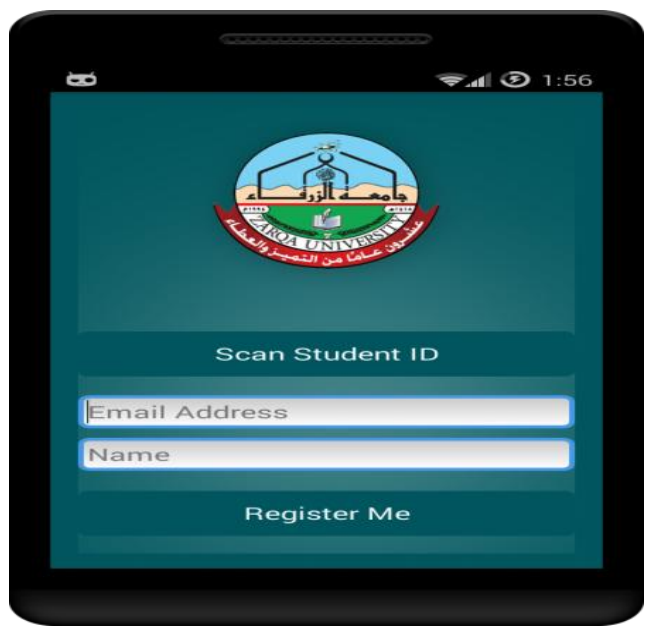

Fig 3.2 : Register Screen

Only the registered student can use the application and must have a university identity card.

If the email is correct and matched with Google account, the student will be registered to the application. The application in turn will send email to the GCM, the GCM Server return register id to student. The register id, name, email and student

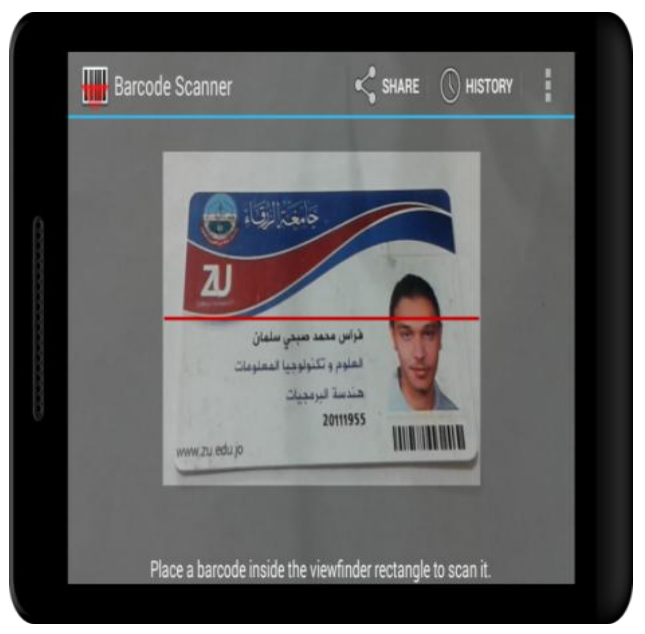

Fig 3.3 : Scan barcode of university identity

ID, will store in the web site data base, if it is not matched, the registration will fail.

Fig 3.4 shows the display message screen on Android mobile. The student will become ready to receive notification or message from Instructor. 


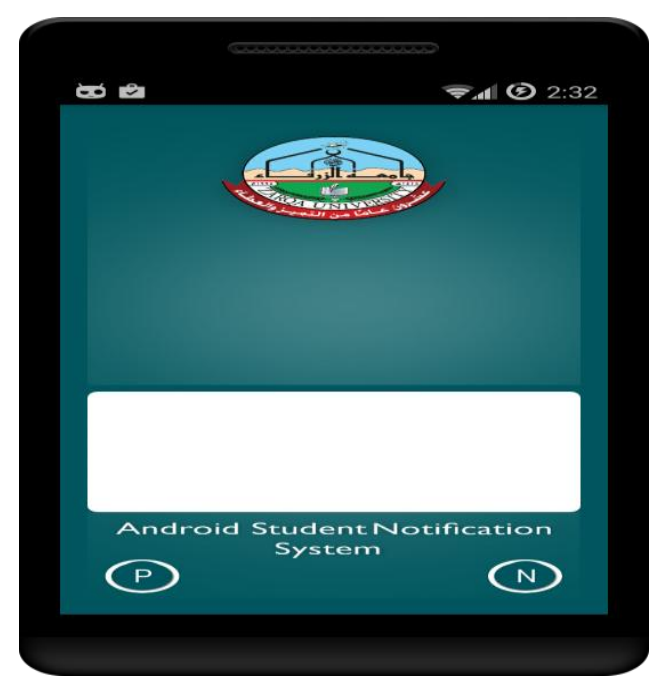

Fig 3.4: display message screen

\subsection{Web application}

The web application (the server side) will be connected to the e-learning application of the university to use the information stored in the database, about instructors, the related courses and sections and student attend them. The instructor will log in by using the login screen page as in Fig 3.5,
Courses will be displayed, choose the course and section (if there is more than one section for this course) as shown in Fig 3.6.

The student name with their Id will display, the instructor choose to whom sending a message or to all, writing the message, and send it as shown in Fig 3.7

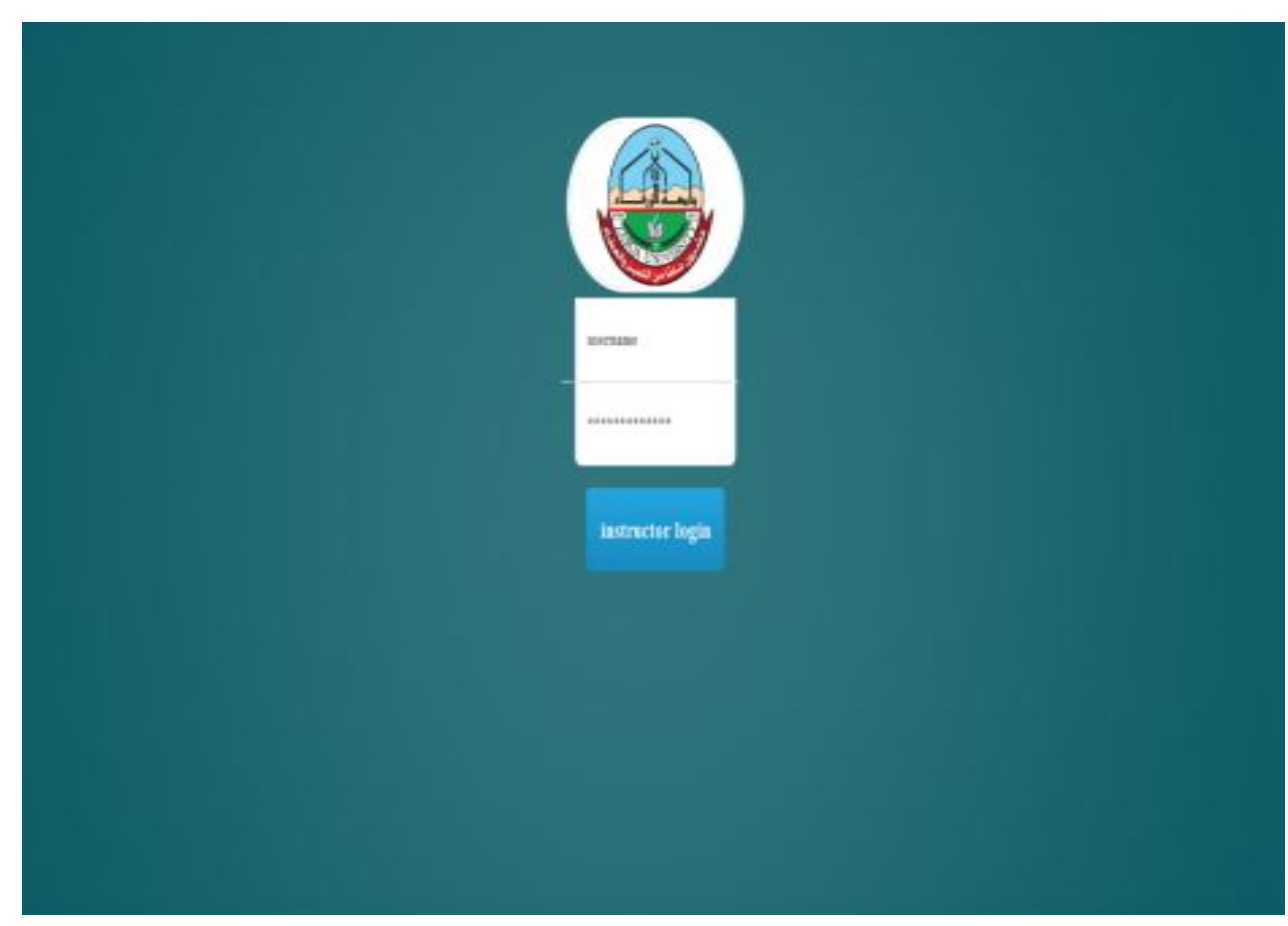

Fig 3.5: Login Screen Page 


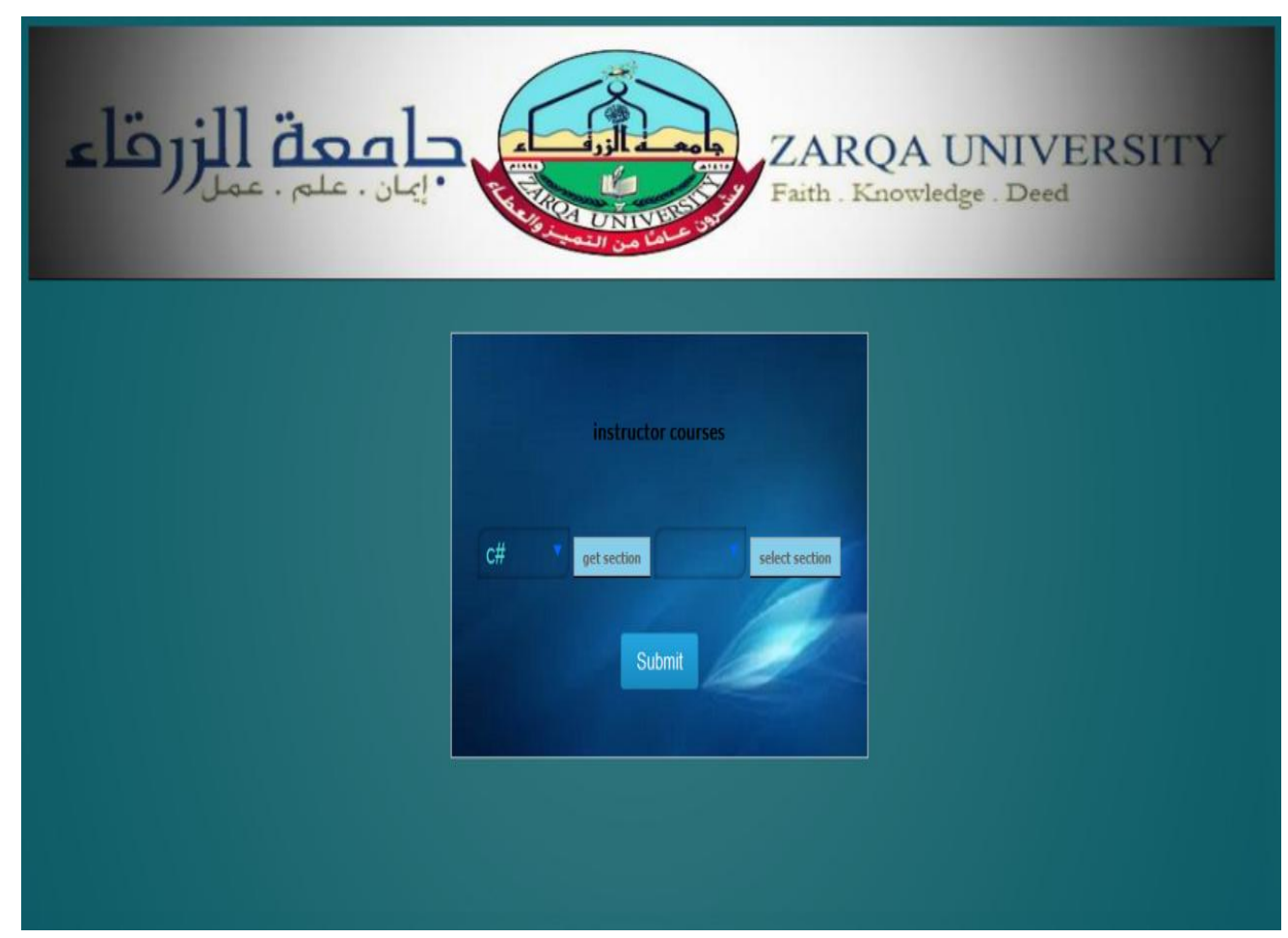

Fig 3.6: get course screen

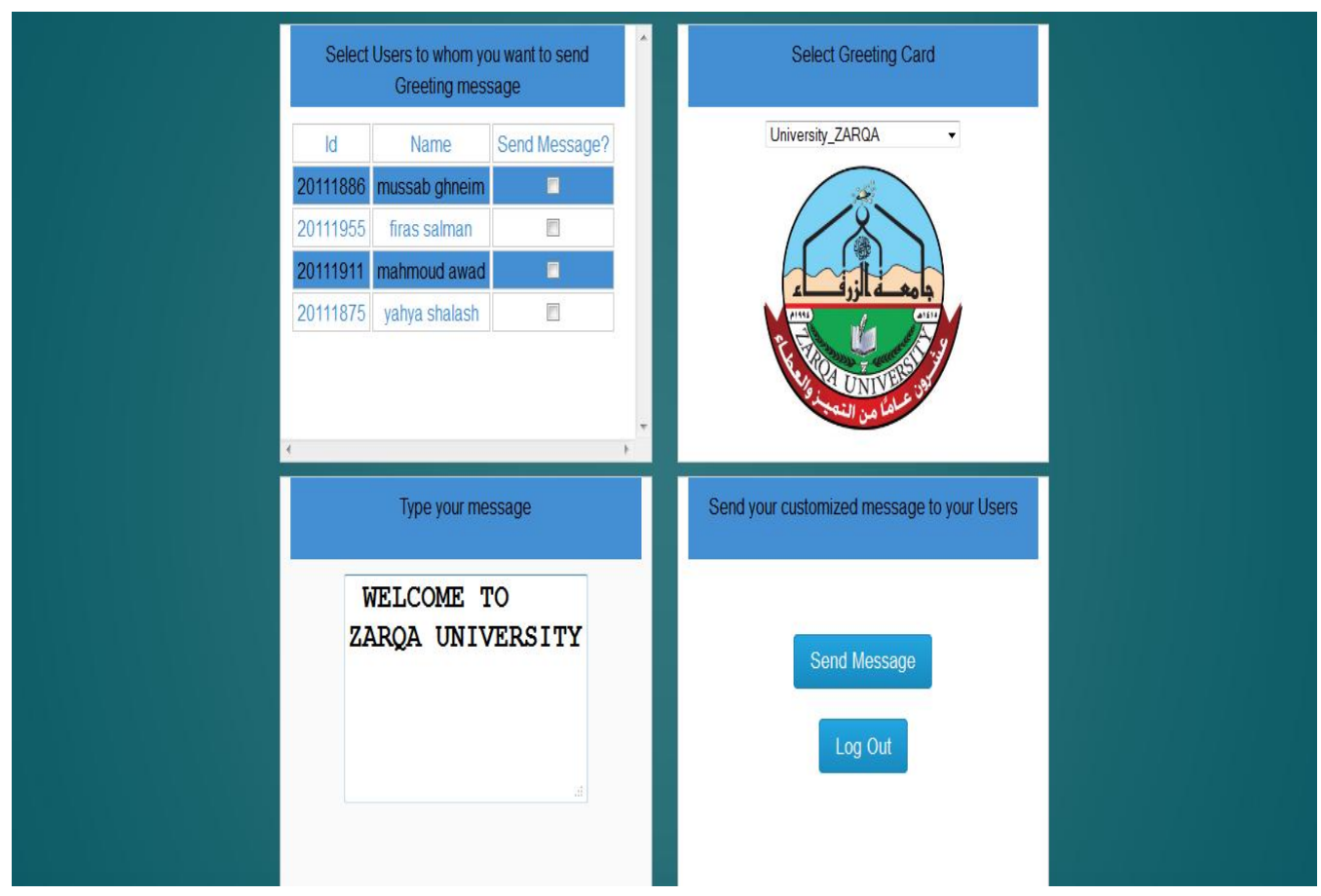

Fig 3.7: Send message

After sending the message to the students, they will receive it on their mobiles as in Fig 3.8, opening the notification will

display the receiving message as shown in Fig 3.9. 


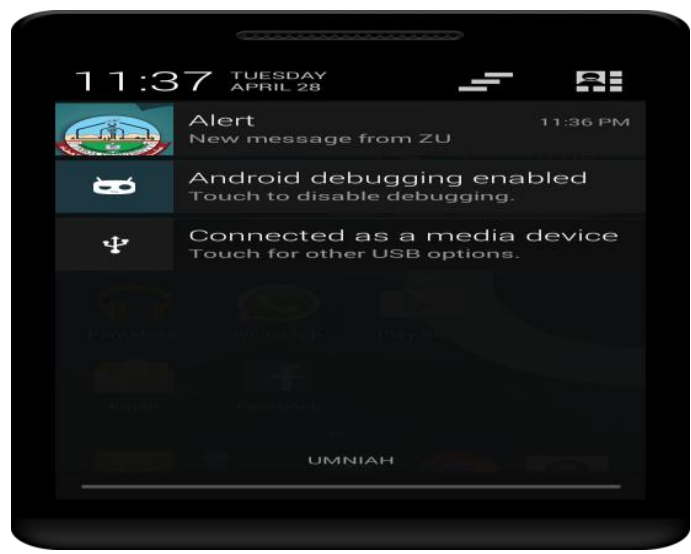

Fig 3.8: Student receive notification

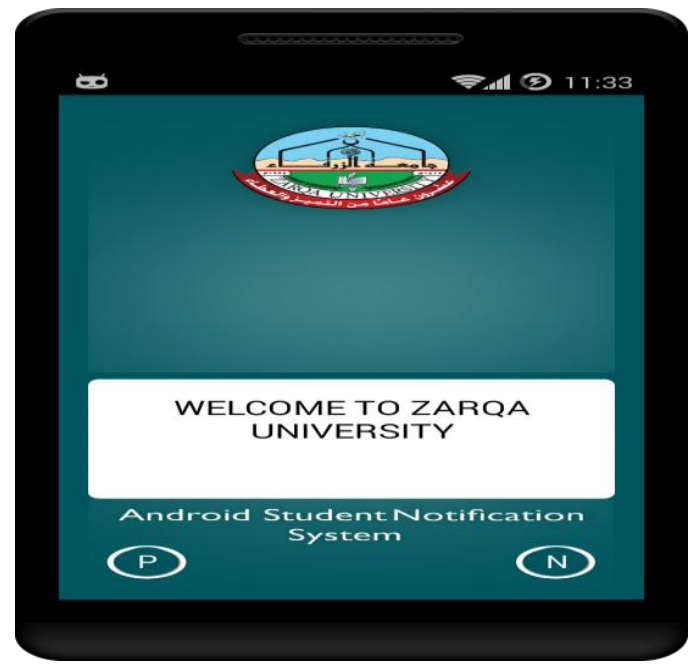

Fig 3.9: Display message from instructor

\section{CONCLUSION}

The objective behind this paper was:

1. Make communication easier and quick between the instructor and his students, by sending notification to their mobiles.

2. Furthermore, the notification send from university web site using GCM message, arrive to students Android mobile at once, so they don't have to use the web site always.

3. Future idea is to develop the application, by including the IOS mobile to the application so all type of mobile phones will be included.

\section{ACKNOWLEDGEMENTS}

My thanks to the programmer of educational center in ZARQA University, also to the clever students (Firas salman, Musaab Guniam) for their support that has added a great deal to substance of this paper.

\section{REFERENCES}

[1] avuz Selim Yilmaz Bahadir Ismail Aydin Murat Demirbas, 2014 "Google Cloud Messaging (GCM): An Evaluation" Globecom - Symposium on Selected Areas in Communications: GC14 SAC Internet of Things, (C)2014 IEEE, pp2847-2852

[2] http://developer.android.com/google/gcm/index.htm

[3] Garima Pandey, Diksha Dani, 2014" Adroid Mobile Application Build on Eclipse", International Journal of Scientific and Research Publications, Volume 4, Issue 2, February 2014, ISSN 2250-3153, www.ijsrp.org.

[4] Suhas Holla, Mahima M Katti, 2012 "Android Based Mobile Application Development And Its Security", International Journal of Computer Trends and Technology- volume3Issue3- 2012,PP 486490,ISSN:2231-2803 http://www.internationaljournalssrg.org

[5] Andy Harris, 2009. PHP 6/ MySQL Programming for the Absolute Beginner, 1st Edition , ISBN-10: 1598637983 | ISBN-13: $9781598637984,2009$.

[6] Li Ma, Lei Gu, and Jin Wang , 2014. "Research and Development of Mobile Application for Android Platform", International Journal of Multimedia and Ubiquitous Engineering Vol.9, No.4 (2014), pp.187-198, ISSN: 1975-0080 IJMUE Copyright @ 2014 SERSC, http://dx.doi.org/10.14257/ijmue.2014.9.4.20.

[7] Wei- Meng Lee, 2012. Beginning Android 4 Application Development, ISBN: 978-1-118-19954-1, March 2012. 